\title{
UN RETRATO BIOGRÁFICO DE DOS ESCULTORES EN LA SOMBRA: LOS HERMANOS MIGUEL JERÓNIMO Y JERÓNIMO FRANCISCO GARCÍA (1576-1639/1644)*
}

\author{
MANUel García LuQue ${ }^{1}$ \\ Universidad de Granada
}

\begin{abstract}
Se elabora una primera aproximación biográfica de los escultores granadinos Miguel Jerónimo y Jerónimo Francisco García, aportando una serie de documentos inéditos como sus partidas de bautismo y defunción y el testamento del primero de ellos. Asimismo, se aportan una serie de noticias y piezas desconocidas que perfilan con mayor nitidez el carácter y alcance de su obra en terracota, clave en la transición del manierismo al primer naturalismo en la escultura andaluza.
\end{abstract}

Palabras clave: Hermanos García; Miguel Jerónimo; Jerónimo Francisco; escultura granadina; terracota; Granada; Siglo XVII

\section{A BIOGRAPHICAL PORTRAIT OF TWO SCULPTORS IN THE SHADOWS: THE BROTHERS} MIGUEL JERÓNIMO AND JERÓNIMO FRANCISCO GARCÍA (1576-1639/1644)

This paper offers a first biographical note on the $17^{\text {th }}$-century sculptors of Granada Miguel Jerónimo and Jerónimo Francisco García, through the use of previously unpublished documents such as their baptismal and death certificates or the will of Miguel. Furthermore, the author presents unknown information and pieces that help to understand more clearly their work in terracotta, fundamental in the transition from Mannerism toward Naturalism in Andalusian sculpture.

Key words: García brothers; Miguel Jerónimo; Jerónimo Francisco; Granada sculpture; terracotta; Granada; 17th Century.

Cómo citar este artículo / Citation: García Luque, Manuel (2017): "Un retrato biográfico de dos escultores en la sombra: los hermanos Miguel Jerónimo y Jerónimo Francisco García (1576-1639/1644)”. En: Archivo Español de Arte, vol. 90, núm. 360, Madrid, pp. 365-382. doi: 10.3989/aearte.2017.24

No es exagerado afirmar que el de los hermanos García constituía, hasta hoy, uno de los grandes enigmas de la escultura española. A pesar de que sus obras representan un episodio fundamental en el tránsito del manierismo al primer naturalismo, las fuentes documentales se resistían a aportar cualquier mínimo dato biográfico sobre estos artistas, ignorándose hasta el momento fechas tan esenciales como el momento de su nacimiento y defunción. Los únicos datos

\footnotetext{
* Trabajo realizado en el marco del proyecto I+D "El triunfo del barroco en la escultura andaluza e hispanoamericana" (HAR2013-43976-P), dirigido por Lázaro Gila Medina y financiado por el Ministerio de Economía y Competitividad. El autor desea expresar su agradecimiento a Roberto Alonso Moral, Alfonso Pleguezuelo y Miguel Ángel Marcos Villán por la ayuda prestada para su elaboración.

1 mgarcialuque@ugr.es / ORCID iD: http://orcid.org/0000-0001-9795-5679.
} 


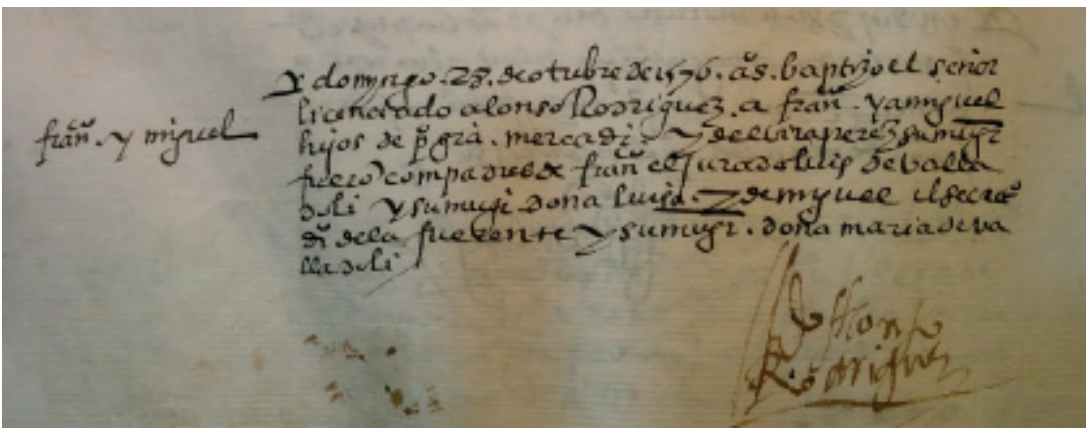

Fig. 1. Partida bautismal de los hermanos García. 28 de octubre de 1576. Archivo Parroquial del Sagrario de Granada, libro $4 .^{\circ} \mathrm{de}$ bautismos, f. $63 \mathrm{v}$.

seguros que se manejaban eran los suministrados por Bermúdez de Pedraza en 1608. A saber: que se llamaban Jerónimo Francisco y Miguel Jerónimo, que eran hermanos gemelos y que en aquel tiempo se encontraban activos en Granada modelando esculturas en cera ${ }^{2}$. Desde entonces lo único cierto que había podido añadirse al conocimiento de sus vidas es que eran hijos de Pedro García, y que en 1623 donaron una escultura del Crucificado a la catedral ${ }^{3}$.

Emilio Orozco se topó de frente con esta problemática en 1934, cuando rescató la obra de los García en un artículo pionero, que supuso una firme base para todos los estudios posteriores ${ }^{4}$. A pesar de las importantes carencias documentales, Orozco consiguió rehabilitar la memoria de estos hermanos granadinos gracias a la identificación de una obra mencionada por el conde de Maule, que le sirvió de punto de partida para vincular con su producción un homogéneo grupo de esculturas en barro. Desde entonces este catálogo no ha parado de incrementarse, especialmente gracias a las importantes aportaciones de la última década, pero sin embargo nada nuevo había podido añadirse al conocimiento de sus exiguas biografías 5 . Ahora, el hallazgo de un importante volumen de datos de archivo nos permite paliar esta laguna, esbozando una primera aproximación biográfica sobre estos artistas y dando a conocer algunas obras inéditas que perfilan con mayor nitidez el carácter y alcance de su producción.

\section{Memoria de un olvido}

Los hermanos Jerónimo Francisco y Miguel Jerónimo nacieron en el otoño de 1576, pues fueron bautizados el 28 de octubre en la parroquia del Sagrario de Granada (fig. 1) ${ }^{6}$. Pertenecen, por tanto, a la misma generación que Gregorio Fernández, son un poco más jóvenes que Martínez Montañés (1568), y algo mayores que Juan de Mesa (1583) o Alonso de Mena (1587).

Sabemos con toda seguridad que eran gemelos, pues Pedraza afirmaba que eran tan semejantes "en lo natural de la edad, cuerpo y partes naturales, que es menester señalar el vno para conocer el otro"7. Aunque en la partida bautismal sólo se registran como Francisco y Miguel, compartieron un segundo nombre, Jerónimo. Es posible que lo tomaran tras recibir el sacramento de la confirmación, pero tampoco hay que descartar que hubieran nacido un 30 de septiembre,

2 Bermúdez de Pedraza, 1608: 133.

3 Domingo Sánchez-Mesa en Salas, 1966: 31, n. 57. Precisó la fecha Gómez-Moreno Calera, 2005: 158.

4 Orozco Díaz, 1934.

5 Romero Torres, 2009 y 2015. López-Guadalupe Muñoz, 2010. Alonso Moral, 2010.

${ }^{6}$ Archivo de la Parroquia del Sagrario, Granada (APSG), L. Bautismos 4, f. 63v: "[Francisco y Miguel] Domingo 28 de otubre de 1576 años baptizo el señor liçenciado Alonso Rodriguez a Francisco y a Miguel hijos de Pedro Garcia mercader y d[e] Elvira Perez su muger fueron compadres de Francisco el jurado Luis de Valladoli [sic] y su muger doña Luisa y de Miguel el secretario Diego de la Fuerente [sic] y su muger doña Maria de Valladoli [sic]".

7 Bermúdez de Pedraza, 1608: 133. 


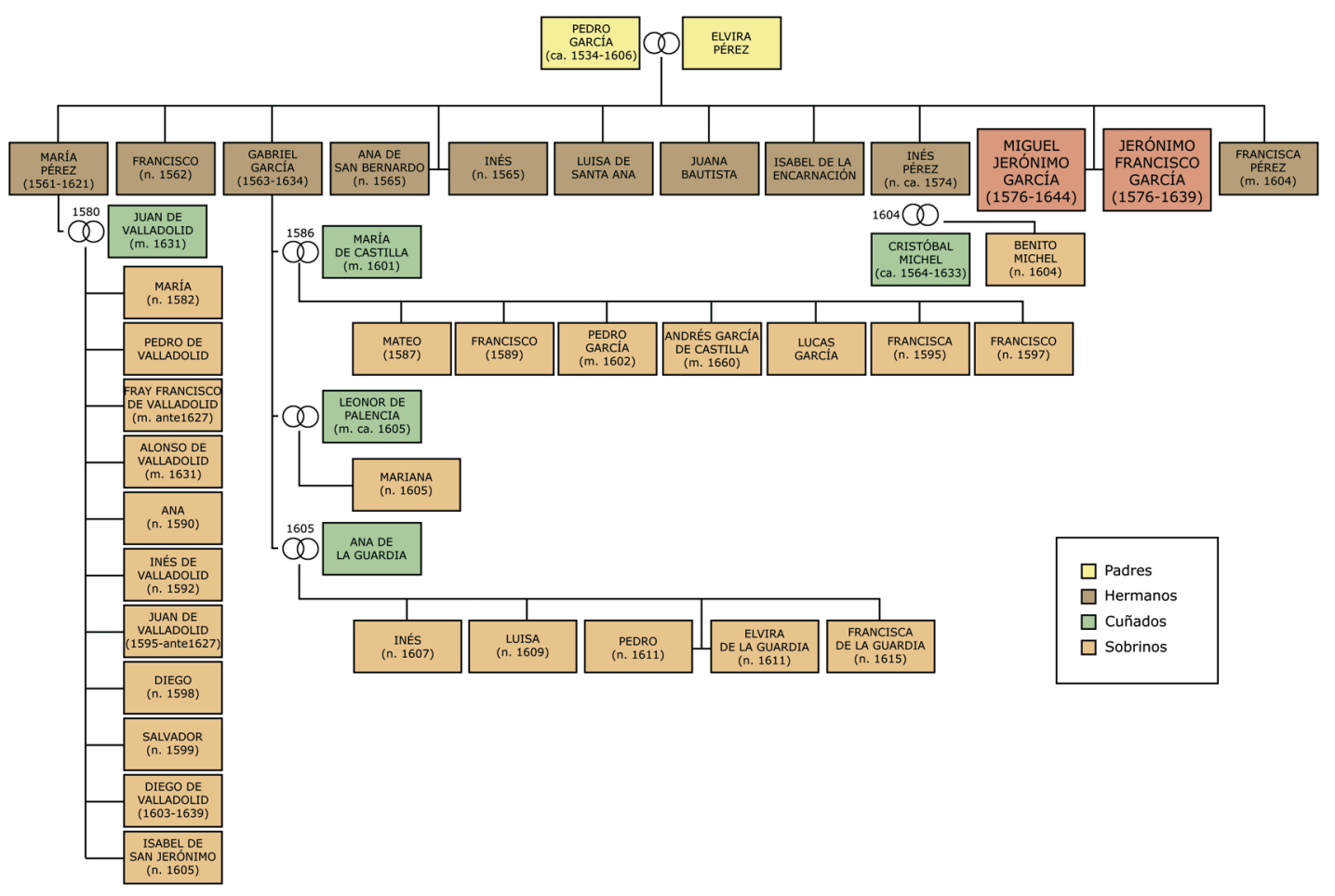

Fig. 2. Árbol genealógico de los García (elaboración propia).

festividad del traductor de La Vulgata, lo que también explicaría la elección de dos onomásticas inmediatas en el calendario: san Miguel (29 de septiembre) y san Francisco (4 de octubre).

Los gemelos eran los hijos menores del matrimonio formado por Pedro García y Elvira Pérez, casados hacia 1560 y padres asimismo de María (1561), Francisco (1562), Gabriel (1563), las gemelas Ana e Inés (1565), Luisa, Juana, Isabel, Francisca e Inés (ca. 1574) (fig. 2) ${ }^{8}$. Se había identificado erróneamente a Pedro García con un albañil ligado a las obras catedralicias, pero en realidad fue un próspero mercader de sedas, nacido en torno a 1534 y con tienda abierta en la alcaicería, en la calle del Tinte?

Para conocer el estatus social de la familia, resulta interesante comprobar que en el bautismo aparecen involucrados otros dos matrimonios: el jurado Luis de Valladolid y su esposa Luisa, padrinos de Francisco, y el secretario de la Chancillería Diego de la Fuente y su esposa María de Valladolid, padrinos de Miguel. Aunque por el momento no es posible determinar su exacto grado de parentesco, a juzgar por la documentación manejada queda claro que los García, los Valladolid y los de la Fuente pertenecieron a una misma parentela, siguiendo una tónica muy habitual en la Granada de aquel tiempo, donde los burócratas de las instituciones locales (ya sea del Cabildo Municipal o de la Chancillería) solían casar con hijas de mercaderes enriquecidos, unos aportando el poder y otras el dinero. El ejemplo más evidente lo representan las propias hermanas de los García: María Pérez, casada con el jurado Juan de Valladolid en $1580^{10}$, e Inés Pérez, casada con el procurador Cristóbal Michel en 160411.

8 APSG, L. Bautismos 2, ff. 118v (María) y 167v (Francisco); L. Bautismos 3, ff. 29r (Gabriel) y 59r (Ana e Inés).

9 En 1604 declara tener 70 años en el expediente matrimonial de su hija Inés Pérez y Cristóbal Michel. Archivo Histórico Diocesano de Granada (AHDG), Expedientes matrimoniales de 1604, leg. 36, pieza 89.

10 APSG, L. Desposorios 1, f. 79v.

11 APSG, L. Desposorios 4, f. 122r. 
La mayor parte de noticias documentales sobre los hermanos García proceden de los libros sacramentales de la parroquia del Sagrario, donde suelen aparecer como testigos o padrinos en el bautismo de sus sobrinos. Así, en noviembre de 1597, con veintiún años, actúan como testigos en el bautizo de su sobrino Francisco, hijo de María de Castilla y de su hermano Gabriel García, también mercader de sedas ${ }^{12}$. Al año siguiente, Jerónimo Francisco apadrina a Diego, hijo del jurado Juan de Valladolid y su hermana María Pérez ${ }^{13}$, y en 1599 vuelve a aparecer como testigo en el bautizo de un hijo de éstos llamado Salvador ${ }^{14}$.

Desde entonces se abre un paréntesis de seis años en la documentación, quizás porque los hermanos se encontraran fuera de la ciudad. No es hasta el 14 de marzo de 1605 cuando Jerónimo Francisco y Miguel Jerónimo vuelven a aparecer entre los testigos del bautizo de su sobrina Mariana, hija de su hermano Gabriel y de Leonor de Palencia, su segunda mujer, que debió fallecer poco después ${ }^{15}$. Este año quedó marcado por otros acontecimientos luctuosos, como la muerte en mayo de su hermana Francisca, que fallece doncella ${ }^{16}$, y la pérdida de su padre Pedro García en abril del año siguiente ${ }^{17}$. En aquel momento los gemelos aún no habían alcanzado la treintena y su hermano Gabriel asumió el papel de pater familias, heredando los negocios del padre.

Este mercader casaría en terceras nupcias con Ana de la Guardia, cuya hija Inés, nacida en 1607, fue apadrinada por su tío Miguel Jerónimo, actuando Jerónimo Francisco en calidad de testigo ${ }^{18}$. Los hermanos se cambiarán los roles en el bautizo de otra hija de Gabriel, Luisa, que recibió las aguas el 23 de junio de $1609^{19}$. Las buenas relaciones entre los gemelos y su hermano mayor los llevaría incluso a apadrinar a las esclavas de éste. Por ejemplo, el mismo día que Luisa recibió las aguas se aprovechó para bautizar a una esclava morisca llamada Nafla, a la que se puso por nombre María ${ }^{20}$, mientras que dos años más tarde le llegaría el turno a otra esclava llamada Ana María ${ }^{21}$. En ambos casos Miguel Jerónimo y Jerónimo Francisco se alternaron como padrino y testigo. Esta tenencia de esclavas nos da una idea de la bonanza económica la familia, pues los propios artistas también llegaron a tener dos a su servicio.

Un examen de la genealogía de los García demuestra que la familia tuvo una predisposición genética a los partos múltiples. Ya se ha visto cómo entre los hijos de Pedro García y Elvira Pérez hubo un doble caso de gemelismo, pero el fenómeno también se repitió en la siguiente generación. Así, del matrimonio formado por Gabriel y Ana de la Guardia nacieron Pedro y Elvira, "hijos de un vientre", bautizados el 28 de noviembre de 1611. Además de ponerles el nombre de sus abuelos, Gabriel quiso que fueran apadrinados por sus tíos gemelos ${ }^{22}$. Nada tendría de particular el bautizo de otra hija llamada Francisca, en noviembre de 1615, de no ser porque en la partida tan sólo aparece Jerónimo Francisco (que actúa como padrino) pero no Miguel Jerónimo, quizás porque de nuevo se encontrara fuera de la ciudad ${ }^{23}$.

La siguiente referencia a los hermanos corresponde a junio de 1623 , cuando son mencionados en el testamento de su hermana Isabel de la Encarnación, antigua monja del monasterio de la Concepción de Granada, quien declaraba que Jerónimo Francisco y Miguel Jerónimo todavía le adeudaban 400 ducados de la legítima paterna ${ }^{24}$. Isabel no sería la única hermana monja, pues

\footnotetext{
12 APSG, L. Bautismos 6, f. 104v (24-XI-1597).

13 APSG, L. Bautismos 6, f. 138v (20-VII-1598).

14 APSG, L. Bautismos 6, f. 190r (19-VIII-1599).

15 APSG, L. Bautismos 7, f. 243r (14-III-1605).

16 APSG, L. Defunciones 1, f. 172v (2-V-1605).

17 APSG, L. Defunciones 2, f. 12r-v (15-IV-1606).

18 APSG, L. Bautismos 7, f. 319v (1-II-1607).

19 APSG, L. Bautismos 7, f. 429r.

20 APSG, L. Bautismos 7, f. 429r.

${ }^{21}$ APSG, L. Bautismos 8, f. 43v (11-IV-1611).

22 APSG, L. Bautismos 8, f. 66v. Jerónimo Francisco apadrinó a Pedro y Miguel Jerónimo a Elvira.

23 APSG, L. Bautismos 8, f. 268r (23-XI-1615).

${ }^{24}$ APSG, leg. 2, pieza suelta, s/f (28-VI-1623).
} 
Fig. 3. Detalle del Mapa topográfico de la ciudad de Granada por Francisco Dalmau, 1795.

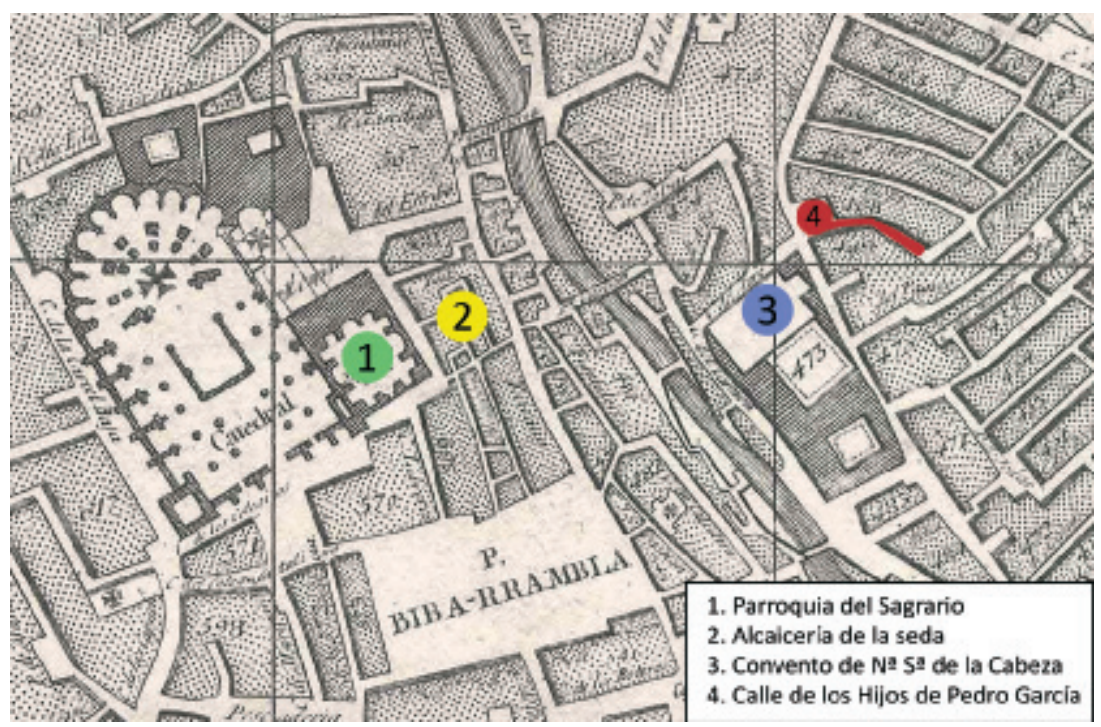

también lo fueron Ana de San Bernardo y Luisa de Santa de Ana, que profesaron en el mismo convento, y Juana Bautista, que lo hizo en el de carmelitas calzadas de la ciudad ${ }^{25}$.

En noviembre de este mismo año Miguel Jerónimo y Jerónimo Francisco hicieron donación a la catedral de un Crucificado de madera sin policromar. El acta capitular se refiere a ellos como "los dos hermanos hijos de Pedro Garcia", asunto que nada debe de extrañar teniendo en cuenta la acreditada fama del padre, como más abajo se verá. En cambio, sí resulta relevante constatar que en ningún momento se hace mención al autor de la obra, indicándose tan sólo que era "de muy buena mano" y que querían donarla "por la mucha devocion que tienen a esta Santa Iglesia" 26 .

Aproximadamente por aquel tiempo, Miguel Jerónimo seguiría los pasos de sus hermanas, ordenándose como clérigo presbítero. La primera referencia documental a su condición eclesiástica corresponde a 1627, cuando su cuñado el jurado Juan de Valladolid nombró por albaceas testamentarios a Jerónimo Francisco y al "licenciado Miguel Jerónimo, clérigo presbítero" 27. Aunque la documentación no alcanza a precisar en qué iglesia ejerció el sacerdocio, parece claro que Miguel Jerónimo no llegó a gozar de ningún beneficio eclesiástico, y ni mucho menos llegó a ser canónigo de la colegiata del Salvador, como equivocadamente consignó Ceán ${ }^{28}$. Sí es posible que llegara a ser capellán de alguna capellanía, circunstancia que en todo caso no recogió en su testamento. De lo que no cabe duda es que solo uno de los gemelos abrazó el estado eclesiástico pues, a pesar de lo que se ha venido repitiendo insistentemente, Jerónimo Francisco murió siendo seglar.

Buena parte de la vida de los hermanos transcurrió en una vivienda a espaldas de la capilla mayor del convento de carmelitas de Nuestra Señora de la Cabeza. La casa hacía esquina con la calle Escudo del Carmen y la actual Horno de San Matías, por entonces conocida como "calle de los hijos de Pedro Garzia", lo que nos da una idea de la popularidad alcanzada por el padre y los hijos en la ciudad (fig. 3). En el padrón de 1635 (el primero conservado) aparecen viviendo en esta casa junto a dos esclavas llamadas Ana de Jesús y María Magdalena y otros desconocidos Bautista.

${ }^{25}$ Es posible que el Ecce Homo de los García que existe en este cenobio ingresara como parte de la dote de Juana

${ }^{26}$ La obra no sería encarnada hasta 1724 (véase nota 3). La estudia en profundidad López-Guadalupe Muñoz, 2009.

27 APSG, leg. 2, pieza suelta, s/f. (6-II-1627). El jurado fallece el 15-VII-1631. APSG, L. Defunciones 5, f. 122v.

28 Ceán Bermúdez, 1800: 162-163. 


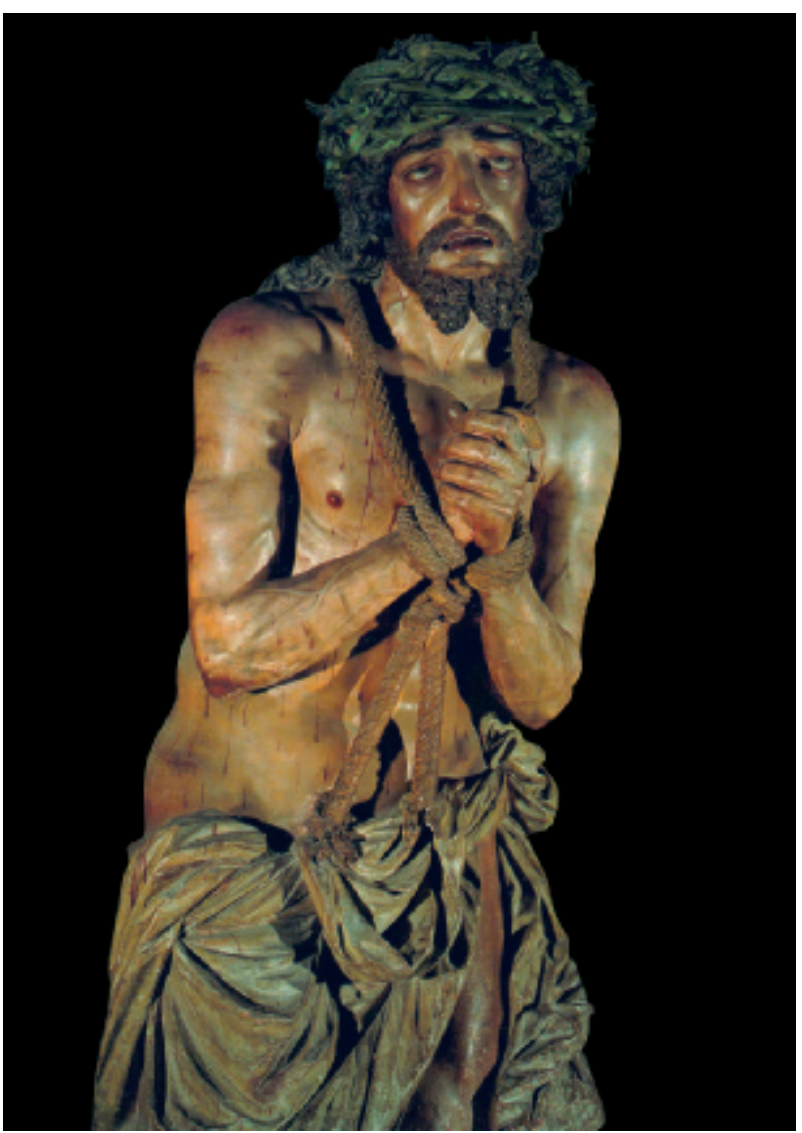

Fig. 4. Hermanos García. Cristo de las Penas, ca. 1620-39. Granada, monasterio de la Cartuja (procedente del convento de N. ${ }^{a}$ S. ${ }^{a}$ de la Cabeza). -quizás criados- que residen intermitentemente en la vivienda, como Andrés Castaño (1635) y Tomás Simón $(1637-38)^{29}$.

Las buenas relaciones que los gemelos mantenían con su hermano Gabriel también se fundamentaban en una cuestión de vecindad, pues este último vivía en la casa de al lado, que había heredado de su padre Pedro García. Tras su fallecimiento, en marzo de 1634 , los gemelos quedarían como albaceas de sus bienes ${ }^{30}$. Cinco años más tarde le llegaría el turno a Jerónimo Francisco, que murió el 3 de octubre de 1639, a los sesenta y dos años, siendo enterrado en la parroquia del Sagrario $^{31}$. Desgraciadamente su testamento, otorgado en 1635, pereció en el conocido incendio del Archivo de Protocolos, pero por referencias indirectas sabemos que dejó por albacea y heredero universal a su hermano Miguel Jerónimo, a quien encomendó que se le dijeran mil misas por su alma y otras mil cuando este último falleciera.

Miguel sobrevivió otros cinco años, tiempo en el que continuó viviendo en la misma casa junto a las dos esclavas $\mathrm{y}$ otras personas que residen de manera discontinua, como los desconocidos Diego Sánchez (1641), Gaspar de los Reyes (1642) o Juan Descalzo (1644) ${ }^{32}$. Finalmente moriría el 20 de febrero de 1644, a los dos de la madrugada, tras sesenta y siete años de vida ${ }^{33}$. A la mañana siguiente se abrió su testamento cerrado, cuyos más de cuarenta folios ilustran a la perfección la mentalidad y el carácter del testador ${ }^{34}$.

29 APSG, Padrones de 1635 (casa 497), 1637 (casa 505) y 1638 (casa 492).

30 APSG, L. Defunciones 5, f. 145v (12-III-1634). Había testado el 13 de octubre de 1617 ante el escribano del rey Pedro de Saavedra, pero lamentablemente el documento no se conserva.

31 APSG, L. Defunciones 5, f. 227r: "Jeronimo Francisco Garcia murio en tres de octub[re] de mill y seissientos y treinta y nuebe años, enterrose en esta yglesia, otorgo su testamento ante Antonio Ruis de Prado, escribano publico, su ffecha en Granada a quince de diciembre de mill y seissientos y treinta y cinco años dejo por albacea y heredero a su ermano el licenciado Miguel Geronimo, de las misas que mando tocaron a la parroquia ciento y el nobenario \&. "."

32 APSG, Padrones de 1641 (casa 464), 1642 (casa 465), 1643 (casa 480) y 1644 (casa 495).

33 APSG, L. Defunciones 6, f. 54r: "El licenziado Miguel Geronimo, presuitero, murio en 20 de fevrero de 44. Otorgo su testamento cerrado, abriosse en dicho dia ante Antonio Ruiz de Prado, escriuano puvlico, dexo por albaceas al lizenciado Juan de la Fuente, beneficiado de Ssan Gil y a don Francisco Balladolid, presuitero, y a don Benito Michel, mandose enterrar en esta yglesia, heredera su alma, mando dos mil misas y mil que el hermano del susodicho luego que el falleciese, que son por todas tres mil missas, tocaron de quarta setecientas y cinquenta y el novenario".

34 Otorgado ante Antonio Ruiz de Prado el 9 de agosto de 1641. El original ardió en el citado incendio, pero se conocen dos copias: una parcial en AHDG, Capellanías, leg. 234-F; y otra completa en Archivo Histórico Nacional, Madrid (AHN), Clero Secular Regular, L. 3563. 
En primer lugar mandó ser enterrado con el hábito franciscano y el escapulario de la Virgen del Carmen en la sepultura de sus abuelos de la parroquia del Sagrario, donde también habían sido inhumados sus padres y su hermano Jerónimo Francisco. Quería que se le dijera misa cantada de cuerpo presente con diácono, subdiácono, vigilia y responso, y que en su entierro lo acompañaran la cruz y curas del Sagrario y del Colegio Eclesiástico, las cofradías de la Limpia Concepción del convento de San Francisco y la de Nuestra Señora del Carmen - de las que se declara cofrade- y que su cuerpo fuera portado por los hermanos del hospital de Juan de Dios. Esta comitiva debía completarse nada menos que con cuarenta y ocho frailes pertenecientes a los conventos de la Cabeza, San Francisco, San Antón y la Santísima Trinidad.

El capítulo de misas resulta extensísimo, encargando que se dijeran dos mil sufragios por su alma y las de sus difuntos, a repartir entre su parroquia y la mayor parte de los conventos masculinos de la ciudad, así como otros mil por el alma de su hermano en cumplimiento de la cláusula testamentaria ya comentada. Respecto a las misas tocantes al convento de la Virgen de la Cabeza, manifestó su deseo de que "las mas dellas [se dijeran] en el altar del Santo Cristo de las Penas" (fig. 4). El vínculo emocional con esta imagen resulta hasta cierto punto lógico, pues se trataba de una obra precisamente realizada por ambos hermanos. Lo mismo ocurre con el Cristo de las Penas de los jesuitas de San Pablo (fig. 5), para el que Miguel Jerónimo mandó una limosna 300 reales para ayuda a dorar su retablo "y si ya estubiere dorado y pagado sean para adorno de el altar" 35 . Además de las cuantiosas mandas hechas a las fundaciones conventuales de la ciudad, de su carácter piadoso y caritativo dan cuenta las limosnas de 30 ducados que dio para repartir entre pobres vergonzantes, otros 30 para vestir a "doze pobres, los mas desnudos que se hallaren" y 80 para casar con personas honradas a dos huérfanas honestas, recogidas y pobres.

Del análisis de su testamento también se desprende que los García gozaron de una holgadísima situación económica. En el momento de testar, el patrimonio de Miguel Jerónimo se componía de tres censos y numerosos bienes inmuebles, entre los que se encontraban doce casas, una tienda frente a la alhóndiga Zaida y la parte proporcional de la tienda que perteneció a su padre en la alcaicería. La casa de su morada fue legada a su sobrino Benito Michel con la condición de que pagara una renta anual de 50 ducados para fundar una capellanía colativa en la parroquia del Sagrario, dejando su patronato en manos de este sobrino y del prior del convento de la Cabeza.

El resto de inmuebles fueron repartidos entre sus sobrinos y las esclavas, a quienes otorgaba la libertad y les garantizaba su sustento mediante el usufructo de cuatro casas cada una. Entre los bienes muebles, destaca el legado a su esclava Magdalena de dos reposteros, los cuadros de la Magdalena y del Cristo a la Columna y una pareja de pinturas con San Jerónimo y San Francisco de medio cuerpo. El lote más importante lo recibió la esclava Ana de Jesús, que se quedó con el otro repostero, "las ymajenes que tiene en su altar", los cuadros del Nacimiento y Santa Teresa y otra pareja de pinturas alargadas con los temas de San José con el Niño de la mano y la Virgen con el Niño, además de otra "imagen de Nuestra Señora que tiene el çerquito redondo". Esta misma esclava también heredaría los libros devocionales de la biblioteca de Miguel Jerónimo: "el libro que es Flosanturon [sic], el de Frai Luis de Granada, y todos los libritos pequeñicos de deuoçion, y los quadernicos tambien, para que algunos ratos lea en ellos y se aproueche para seruiçio de Dios" ${ }^{6}$. En otra cláusula testamentaria, Miguel también menciona poseer "dos cuadros grandes compañeros de San Francisco y San Pedro" que mandaba en donación al oratorio de las beatas de los Santos Mártires.

Por desgracia nada más sabemos de su biblioteca y de su colección de arte, pues no se ha conservado ni el inventario de bienes ni una relación de bienes muebles que el propio Miguel Jerónimo dejó manuscrita de su puño y letra. La biblioteca pasaría a la librería del convento de la Cabeza mientras que el resto de muebles serían vendidos en pública almoneda por sus albaceas, nombrando como tales a su primo el licenciado Juan de la Fuente, beneficiado de San Gil,

\footnotetext{
35 AHN, Clero Secular Regular, L. 3563, f. 37v.

${ }^{36}$ AHN, Clero Secular Regular, L. 3563, f. 29v.
} 
y a sus sobrinos Francisco Ferruz de Valladolid y Benito Michel. El producto de esta venta se invertiría en más misas, limosnas y obras pías, pues Miguel Jerónimo dejaba por únicas y universales herederas a su alma, a las de sus padres y a la de su hermano Jerónimo Francisco.

\section{La escultura, una actividad encubierta}

La documentación aportada resulta sumamente valiosa para reconstruir la biografía de Miguel Jerónimo y Jerónimo Francisco García, pero se resiste a suministrar cualquier mínimo apunte sobre su actividad artística. No se ha conservado -o por el momento, no se ha localizado- ningún documento en que se refieran a sí mismos como escultores -ni siquiera en la donación del Crucificado a la catedral-, como tampoco ningún contrato protocolizado ante escribano; de hecho, dado el formato y el carácter de sus obras, mayoritariamente pensadas para el consumo doméstico, cabe sospechar que muchas fueron entregadas como obsequios a su círculo de amistades y que los encargos quedarían sellados con simples pactos verbales.

Este insistente silencio documental resultaría hasta cierto punto lógico en el caso de un artista diletante, pero la alta calidad de la obra de los García va más allá de quien concibe el arte como una actividad de recreo. López-Guadalupe ha señalado que quizás este mutismo se deba a una cuestión de pudor social ${ }^{37}$, argumento que resulta plausible teniendo en cuenta la condición de eclesiástico que ostentaba Miguel Jerónimo y su pertenencia a una familia enriquecida y emergente, con miembros en el cabildo municipal y contactos con la élite cultural de la ciudad. En este sentido, la práctica de un oficio menestral como la escultura podía constituir un lastre para quien aspiraba al estatuto de nobleza.

Por fortuna, aunque los García no se identifiquen como escultores sí lo harán sus contemporáneos. Pedraza los ponderó como "los mayores estatuarios de cuerpos de zera que ay en Europa", añadiendo que "no ay estrangero de ninguna nacion, que no les reconozca superioridad, porque la destreza y viuo con que las hazen, parece que excede la capacidad humana" 38 . También suscribe su actividad como ceroplastas el poeta Agustín Collado del Hierro, en cuyo poema Granada dedica unas enrevesadas octavas a los dos hermanos capaces de "formar en espirales sumas/ almas en cera" 39 .

A pesar de estos elogiosos panegíricos nada se ha logrado identificar de esta temprana producción en cera, pues el San Jerónimo del palacio arzobispal de Granada ${ }^{40}$-en todo semejante a otro conservado en las clarisas de Monforte de Lemos- parece obra italiana. Sin embargo, sí conviene destacar que el jurado Juan de Valladolid, cuñado de los artistas, poseía en su colección un San Francisco realizado en cera que legó por vía testamentaria al franciscano padre Fustero ${ }^{41}$. Aunque en el documento nada se dice del autor, se trataría muy probablemente de una obra de los García, cuyo paradero resulta difícil rastrear ante tan escueta descripción.

Es posible que la propia fragilidad de la cera haya contribuido a la desaparición de muchas de estas piezas, pero tampoco sería de extrañar que algunas de sus miniaturas en barro hubieran sido confundidas con esculturas en cera ${ }^{42}$. Además, todo apunta a que sus trabajos en cera pertenecen a sus primeros años de actividad. Así se deduce de una silva laudatoria sin fechar que les dedicó el eclesiástico Pedro de Araujo Salgado y que Palomino pudo ver impresa entre los papeles del pintor Juan de Alfaro ${ }^{43}$. Su reciente localización por Sánchez Rivera constituye todo un

37 López-Guadalupe Muñoz, 2010: 230.

38 Bermúdez de Pedraza, 1608: 133.

39 Collado del Hierro, 2005: 275. El poema, sin fechar, tuvo que terminarse antes de 1634, pues su autor fue enterrado el 3 de mayo de este año en el convento de S. Agustín de Granada. APSG, L. Defunciones 5, f. 147v.

${ }^{40}$ López-Guadalupe, 2010: 237.

41 APSG, leg. 2, pieza suelta, s/f (6-II-1627).

42 Orozco Díaz, 1935. Sobre estas miniaturas, véase López-Guadalupe Muñoz 2010: 225-229.

43 Palomino, 1724: 356. 
hallazgo, pues permite resolver algunas de las incógnitas sobre la producción de los hermanos García $^{44}$.

En primer lugar, el poema, cargado de figuras mitológicas y alusiones neoplatónicas, resulta de enorme interés para reconstruir el ambiente teórico e intelectual en el que se movieron los artistas. En él no faltan las habituales alusiones al paragone entre escultura y pintura, "dos artes soberanas / hijas de vn parto", cuya importancia se equilibra en "Geronimo, y Miguel que vn mismo dia / en gracia mejoraron lo Garcia", pues "vno a los bultos dâ valiente forma, / y otro en lo colorido los informa".

Los siguientes versos señalan explícitamente que inicialmente los hermanos se dedicaron al modelado en cera ("O quanto la primera / materia en que los dos se exercitaron / de la flexible cera / fama de bronce ya se acumularon") y que también trabajaron obras en madera ("No perdonò al formon su diestra mano / en dar forma sagrada al rudo tronco"), aunque finalmente se decantaran por el barro como material predilecto ("y imitando los dos la accion primera / cambian el tronco rudo, y blanda cera / en barro, a Dios remedan felizmente / con esta diferencia"). El poeta aprovecha esta elección para compararlos con Dios creador que, siguiendo el mito mesopotámico, formó al primer hombre del barro, con la salvedad de que ellos "infundir no pueden alma pura / en la Sacra escultura".

Aun sin detenerse en obras concretas, la silva menciona entre las obras en cera el "perfeto desnudo" que "aun el Ticiano auentajar no pudo", refiriéndose quizás a algunas anatomías realizadas en cera (como las que según Pacheco realizaba en Sevilla el escultor Gaspar Núñez Delgado ${ }^{45}$. En el campo de la madera, es segura la alusión al Crucificado de la catedral de Granada cuando Araujo se refiere "al que en la Cruz clauado / murio, del mismo Christo fiel traslado", pero también señala la existencia de alguna escultura del Niño Jesús realizada en madera de boj ("y de su infancia efigie tan hermosa / en el palido box tanto imitaron") de difícil identificación ${ }^{46}$. Más imprecisos son los versos referentes a la obra en barro, limitados a contrastar la representación de Cristo "glorioso" o en "acciones dolorosas", aunque resultan tremendamente reveladores para conocer el impacto emocional que causaban sus dramáticas representaciones del Ecce Homo,

Qual coraçon diamante

de barbaro ignorante

lagrimas no distila copiosas;

que tanto Sol derrite el yelo duro

del pecho mas impuro,

Si, como afirma Araujo, cada hermano se había especializado en una modalidad artística, ¿quién era el escultor y quién el pintor? La respuesta quizás se encuentre en otra noticia, hasta el momento ignorada, sobre el colegio jesuítico de San Pablo en Granada. Según una crónica de hacia 1640, en aquel mismo año se consagró un nuevo retablo para la Inmaculada, realizado por el hermano Díaz del Ribero, ya que el antiguo altar se reservó "para el Santo Cristo [de las Penas], pieça maravillosa de grande deuocion. $Y$ es muy justo que por ella se venere su artífice, que fue Gerónimo Francisco, hermano de Miguel Herónymo, hombre de su siglo, y de siglo que excede a todos los pasados" (fig. 5) ${ }^{47}$. La importancia de este testimonio contemporáneo resulta capital, pues permite intuir que fue Jerónimo Francisco quien se dedicó preferentemente a la escultura, quedando Miguel Jerónimo como el especialista en policromía -tarea menos fatigosa

${ }^{44}$ En gracia de los dos insignes hermanos Miguel, y Geronimo Garcia, varones singulares en la escultura, y pintura. Sylba por Pedro de Araujo y Salgado [s.a. s.n.]. Biblioteca Nacional de España, Ms. 19639, ff. 51r-54v. Cit. en Sánchez Rivera, 2015: 247, n. 10.

45 Alonso Moral, 2010: 327.

46 Estos versos dan nuevos argumentos a la problemática atribución del San Juanito de la catedral de Granada, tallado en madera.

47 AA. VV., 1991: 95. 


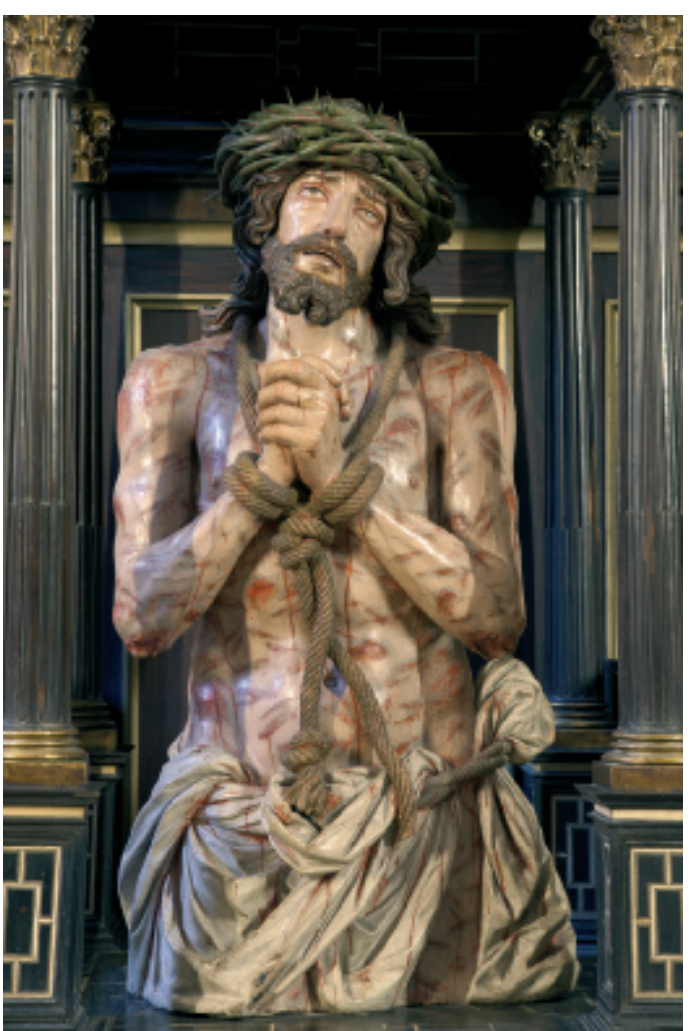

Fig. 5. Hermanos García. Cristo de las Penas, ca. 1620-1639. Granada, iglesia de San Pablo (actual parroquial de los Santos Justo y Pastor).

que casaría mejor con su condición de eclesiástico-, aun sin descartar que en sus inicios ambos se hubieran dedicado al modelado en cera como afirmaba Araujo.

Por otro lado, la noticia viene a confirmar la atribución recogida por Maule dos siglos más tarde ${ }^{48}$, quien acertó en la identificación de sus autores pero confundió el soporte de la obra (es terracota y no madera) y también su iconografía, pues a pesar de lo que se ha venido repitiendo este tipo de bustos largos no reproduce la iconografía del Ecce Homo, sino el episodio apócrifo de la oración en el Gólgota antes de la crucifixión ${ }^{49}$.

Al igual que el Crucificado de la catedral, la obra plantea no pocos interrogantes sobre la formación de los escultores, merced a su enorme dependencia con lo sevillano. El protagonismo de la gruesa corona de juncos pintada en verde, con el cabello ensortijado entre las ramas, dimana de las experiencias previas de Juan de Mesa y Martínez Montañés, por más que el detalle parta de una misma fuente de inspiración en los grabados de Durero ${ }^{50}$. Otro tanto podría decirse de la disposición del sudario, anudado con una gruesa cuerda, que se relaciona muy de cerca con los modelos de Mesa, o el cruento detalle de la espina que atraviesa la ceja, también presente en obras del cordobés. Sánchez-Mesa intuyó que este tipo de pormenores escabrosos, como los codos descarnados que dejan el hueso a la vista, podían tener su inspiración en tratados de meditación como el de fray Luis de Granada ${ }^{51}$, interpretación que ahora cobra todo fundamento al conocer que la obra del escritor dominico se encontraba entre las lecturas devocionales de Miguel Jerónimo.

\section{Terracotas seriadas del Ecce Homo y la Dolorosa}

Uno de los factores que permitió a Orozco elaborar el primer catálogo razonado de los artistas fue la existencia de otras dos versiones del Cristo de las Penas (una en la Cartuja, procedente del convento de la Cabeza ${ }^{52}$ y otra en el Santo Ángel), pero también la presencia de una segunda terracota en la parroquia de los Santos Justo y Pastor que, con buen criterio, atribuyó a la labor de los hermanos barristas. Se trata de un altorrelieve del Ecce Homo que hace las veces de portezuela del sagrario, representado de medio busto y casi de perfil al espectador, con la mirada agachada y los brazos cruzados sobre el pecho, siguiendo una disposición que también remite a las fórmulas difundidas por las estampas de Durero ${ }^{53}$. De este barro Orozco encontró tres réplicas

\footnotetext{
48 Cruz y Bahamonde, 1812: 235.

49 Carrero Rodríguez, 1991.

50 García Luque, 2013: 200.

51 Sánchez-Mesa Martín, 1991: 124.

52 López-Guadalupe Muñoz, 2010: 220-221.

53 García Luque, 2013: 202.
} 


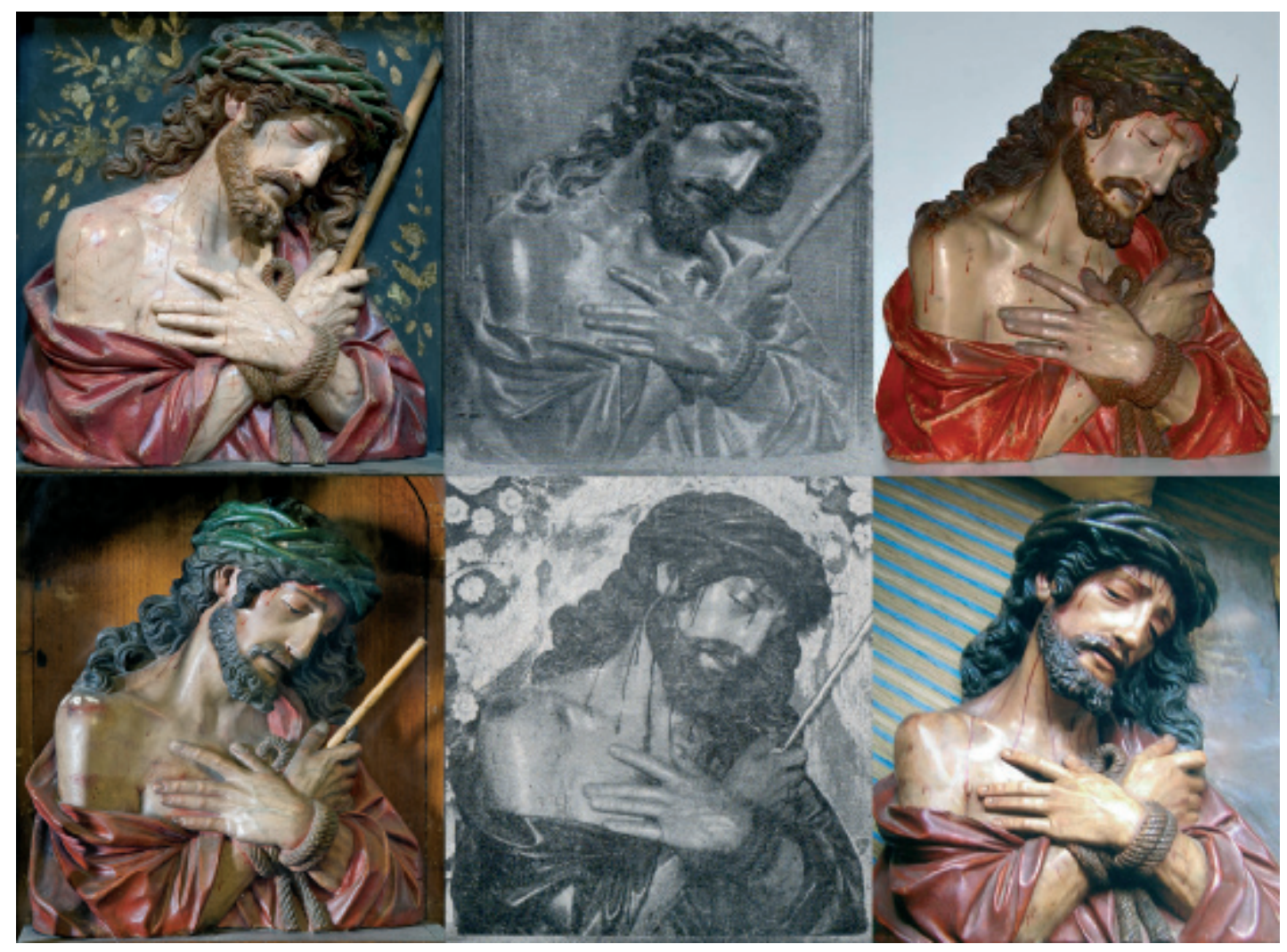

Fig. 6. Hermanos García. Ecce Homo (de izqda. a dcha. y de arriba abajo): Granada, ig. de los Santos Justo y Pastor, convento de los Ángeles y convento de Carmelitas Calzadas; Córdoba, ig. de la Fuensanta; antes en Granada, convento de Santa Inés; Aguilar de la Frontera, col. particular.

casi exactas en los conventos granadinos de Santa Inés y los Ángeles y en la iglesia de San Bartolomé de Jaén, éste muy alterado ${ }^{54}$, a los que se han ido sumando luego el de las carmelitas calzadas de Granada y el de la sacristía del santuario de la Fuensanta de Córdoba ${ }^{55}$, o el hasta ahora inédito de colección particular en Aguilar de la Frontera (Córdoba) (fig. 6).

Algunos de estos eccehomos aparecen emparejados con altorrelieves de la Dolorosa, análogos en formato y soporte, que compositivamente suponen una recreación especular de aquéllos (fig. 7). Al margen de constituir una referencia fundamental para conocer los tipos femeninos de los García, su existencia demuestra que ya desde comienzos del siglo XVII comenzó a difundirse el binomio Ecce Homo-Dolorosa en la escultura granadina, dando respuesta así a las nuevas prácticas devocionales derivadas de la Contrarreforma. No está claro si la aparición de este nuevo tipo de imagen devocional, pensada para el rezo y la meditación en la intimidad del oratorio, se vio influida por la llegada a Granada de otra serie de cabezas del Ecce Homo en barro, relacionadas con el entorno de Gaspar Núñez Delgado, que a veces aparecen acompañadas por bustos de Dolorosa. Pero de lo que no cabe duda es que estas tempranas experiencias de los García constituyeron un referente de primer orden para los famosos bustos de Pedro

54 Orozco Díaz, 1934: 281.

55 López-Guadalupe, 2010: 219-220. García Luque, 2013: 202-203. 


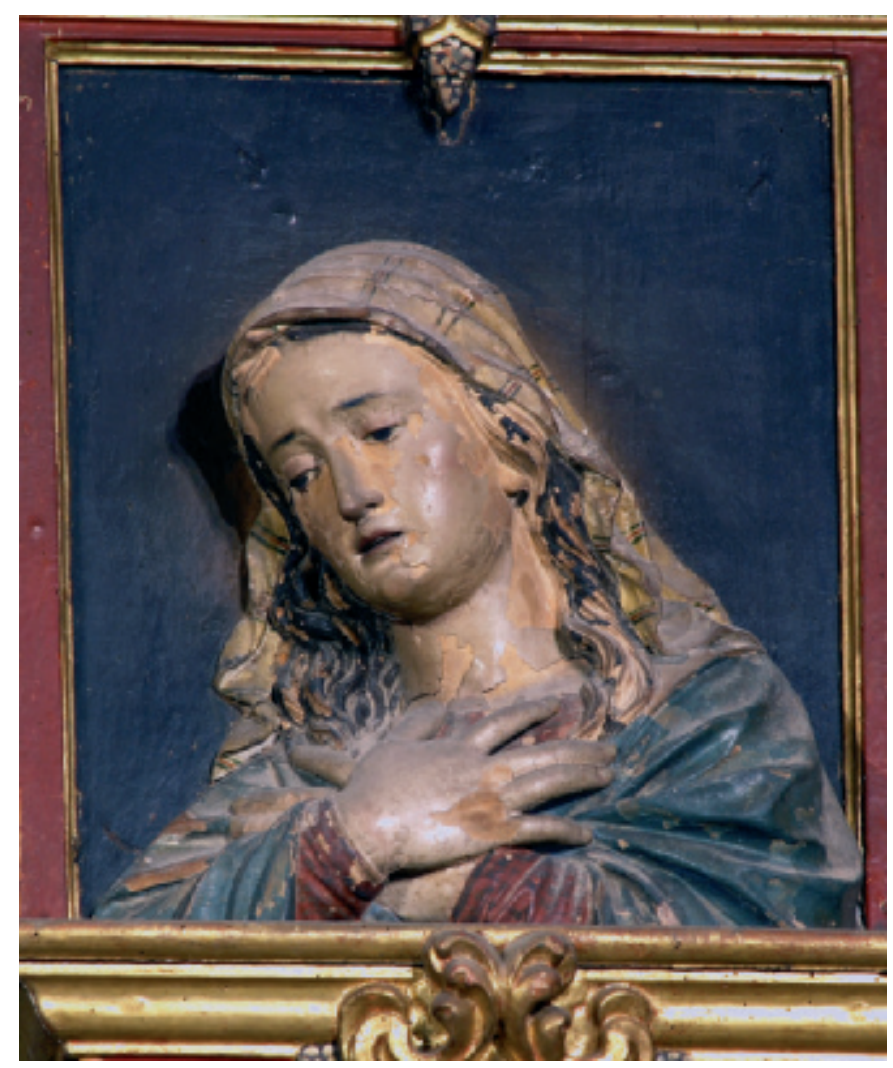

Fig. 7. Hermanos García. Dolorosa, primer tercio del siglo XVII. Granada, convento de los Ángeles. Fotografía: Carlos Madero.

de Mena y José de Mora, que elevarán el género a signo distintivo de la escultura barroca granadina.

La coincidencia en técnica, formato, material y medidas (unos $36-38 \mathrm{~cm}$ de alto) de estos siete eccehomos no es casual, pues como ha estudiado Alonso Moral tuvieron que ser realizados mediante procesos de seriación por molde ${ }^{56}$. Este método de trabajo facilitaba la posterior reutilización del modelo y permitía retocar las piezas cuando el barro aún se encontraba fresco. Con este último repaso se mejoraba la definición de aquellos detalles que exigían un tratamiento más minucioso, como el modelado del cabello o la barba, pero también permitía introducir variaciones en la expresión y el gesto. Es lo que ocurre, por ejemplo, con un busto de Ecce Homo existente en Priego de Córdoba ${ }^{57}$ y otro inédito altorrelieve en la iglesia de San Francisco de Ceuta (fig. 8). Sus sorprendentes semejanzas en el tipo humano y el plegado de la clámide se deben al uso de un mismo molde, aunque a la pieza prieguense se le inclinó la cabeza y se le prolongó el busto antes de cocerla en el horno ${ }^{58}$.

Como alternativa al exitoso modelo de los eccehomos maniatados conviene considerar otro conjunto de altorrelieves de busto corto, sin brazos, cuyas cabezas viran hacia el frente para concentrar la carga expresiva en la mirada. Los ejemplares pertenecientes a esta segunda modalidad superan de largo la veintena, pero su calidad es muy desigual y conviene ser cautelosos a la hora de considerar todo el grupo como obra de los García. El mejor ejemplar de todos es el Ecce Homo conservado en el monasterio de la Concepción de Granada, de formato reducido y

\footnotetext{
56 Alonso Moral, 2010: 339.

57 Villar Movellán, 1983: 109.

58 El ejemplar ceutí, con fondo repintado, funciona como portezuela del sagrario en un retablo colateral.
} 

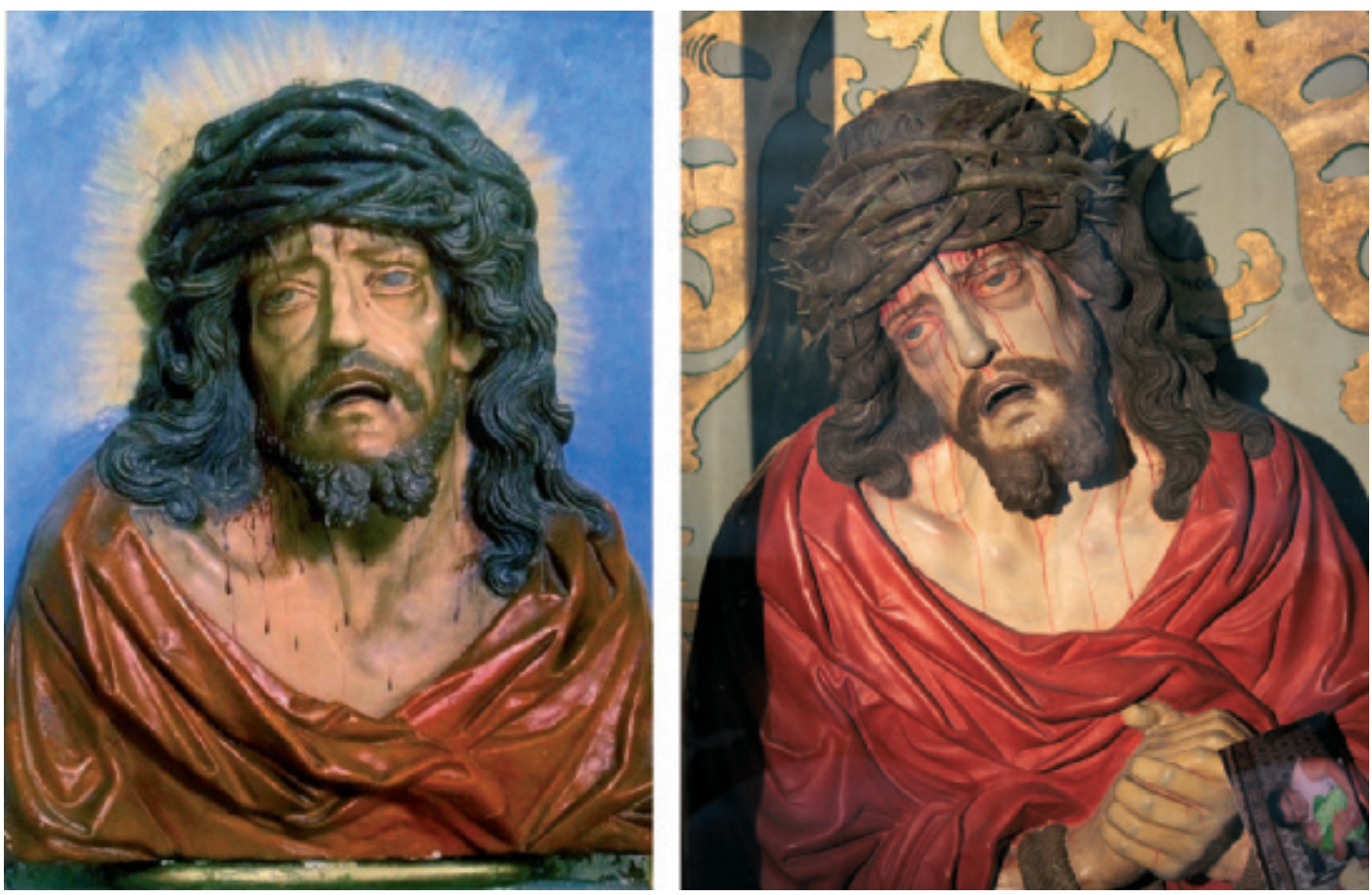

Fig. 8. Hermanos García. Ecce Homo. Ceuta, iglesia de San Francisco (izqda.) y Priego de Córdoba, iglesia de San Francisco (dcha.).

con policromía de subida calidad, que seguramente formaba pareja con otro busto de Dolorosa ${ }^{59}$. De este Cristo, singularizado por la soga al cuello, no se conoce ninguna réplica por lo que no está claro que fuera realizado con molde.

En cambio, existen otros tres eccehomos que evidentemente sí fueron extraídos de la misma plantilla: uno aparecido recientemente en comercio de arte, otro en el hospital de Mujeres de Cádiz y otro, desaparecido, que estuvo en la iglesia de S. Francisco en Jerez de la Frontera ${ }^{60}$. Los tres parecen reproducir en tono menor un modelo original de los García, ejemplarmente representado en un desconocido Ecce Homo de la colección Ajsaris de Granada que, como éstos, anuda su clámide sobre el hombro izquierdo y en lugar de adosarse a un tablero posee fondo realizado en el mismo barro ${ }^{61}$.

Este segundo modelo también resultó muy exitoso, merced a la cantidad de copias que se conservan formando pareja con una Dolorosa también dispuesta frontalmente. A las cinco parejas que ya se conocían ${ }^{62}$, cabe añadir ahora otras tres inéditas (una en el monasterio de Santa Clara de Montilla ${ }^{63}$, otra en el santuario cordobés de la Fuensanta (fig. 9) ${ }^{64}$ y otra

59 Orozco Díaz, 1934: 281. En depósito del ayuntamiento de Granada, procede del convento del Ángel. Posee una leyenda de indulgencias concedidas por el arzobispo don Pedro Ángel Barroeta (1751-1758), donde también se menciona a una Dolorosa.

${ }^{60}$ López-Guadalupe Muñoz, 2010: 220. Romero Torres, 2015: 62-67.

61 El fondo se encuentra parcialmente destruido.

62 Iglesias de la Alhambra (Granada) y S. Ignacio (Morón de la Frontera, desaparecidos), comercio de arte, col. de Ricardo Sierra (Sevilla) y carmelitas de Alcalá de Henares. López-Guadalupe Muñoz, 2010: 219. Sánchez Rivera, 2015: 249.

$6325 \times 30 \mathrm{~cm}$. Mal catalogados como óleos sobre lienzo en Bernier Luque et al., 1993: 222.

${ }^{64} \mathrm{Se}$ custodian en urnas acristaladas de $40,5 \times 34,5 \mathrm{~cm}$. 

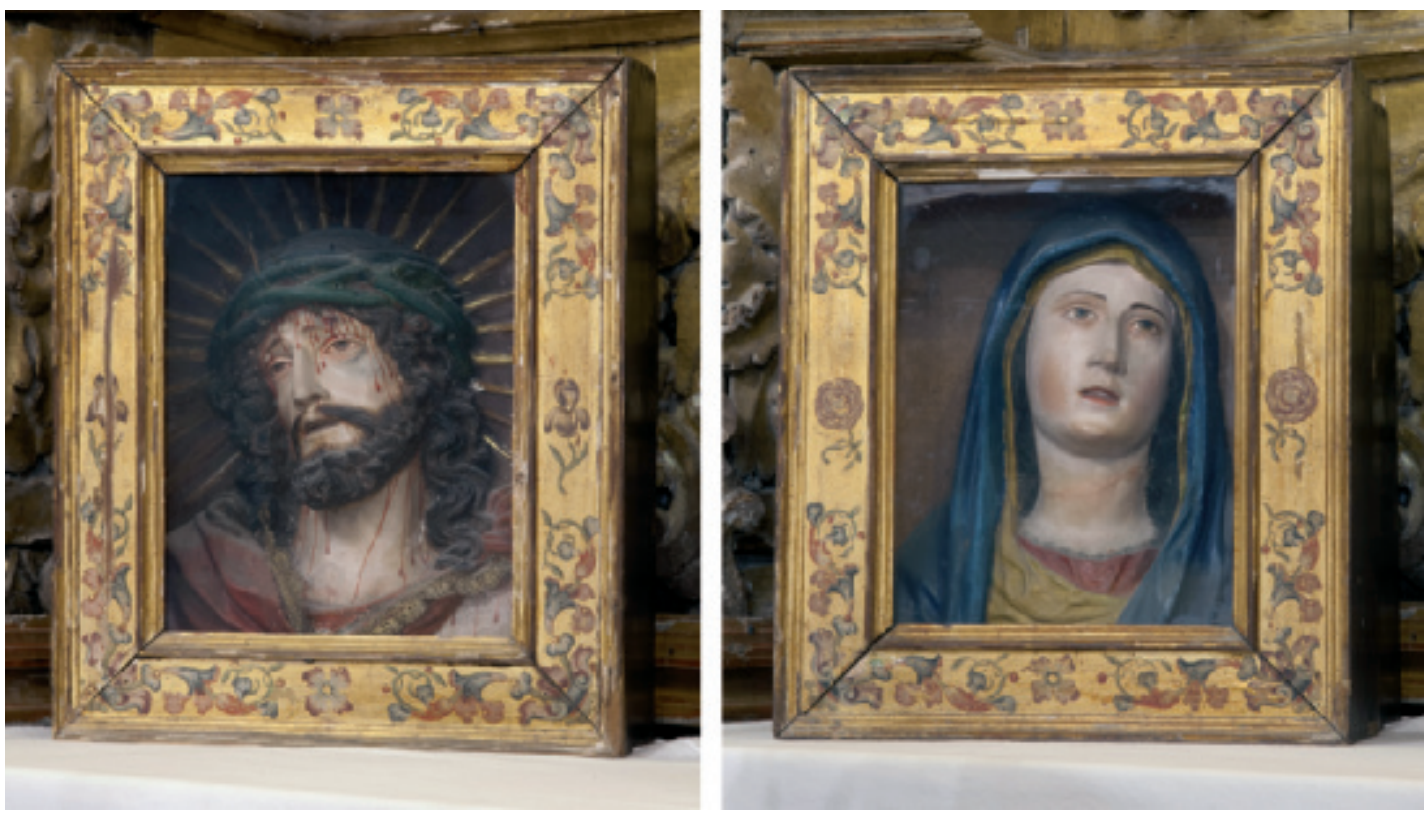

Fig. 9. Copia de los hermanos García. Ecce Homo y Dolorosa. Córdoba, iglesia de la Fuensanta.

en el Museo Casa de los Tiros de Granada ${ }^{65}$ ), además de una cabeza suelta de Dolorosa (Virgen de las Lágrimas en Cabezo de Torres, Murcia) que viene a sumarse al grupo de eccehomos desemparejados ${ }^{66}$. La mayor parte de estas cabezas aparecen simplemente adosadas a un tablero, aunque otras se exhiben en urnas de madera dorada pintadas con motivos florales manieristas típicos de la primera mitad del XVII. Una nota común es la presencia de agremanes textiles y, en algún caso, ojos de cristal introducidos en intervenciones posteriores.

Aunque faltan estudios técnicos de la mayoría de estas piezas, se ha podido comprobar que algunas son simples vaciados en yeso, lo que justifica su excesiva blandura de modelado y la progresiva desvirtuación del modelo. Es muy posible que no sean más que copias realizadas en un taller distinto al de los García a partir de una pareja original en terracota de la que se sacaron moldes, pues resulta difícil admitir que unos maestros que habían alcanzado la excelencia en el modelado del barro y que precisamente no atravesaban dificultades económicas fueran los responsables de esta producción seriada de baja calidad. En apoyo de esta interpretación hay que considerar que las propias fuentes documentales mencionan la existencia de copias. Por ejemplo, en el inventario de bienes de Bernarda de Benavides - hermana del pintor Juan de Sevilla- se registran en 1683: "quatro cauezas en sus nichos con sus bidrieras, copias de los Garcias, dos de Nuestro señor Jesucripto y las otras dos de su Santisima Madre"67.

${ }^{65}$ Ecce Homo (CE00343), 43,5 × 33,5 cm, y Dolorosa (CE00353), 43,5 × 37,6 cm, mal catalogados como tallas en madera del XVIII o XIX.

${ }^{66}$ Tres versiones se conservan en el monasterio de la Concepción de Granada y en los conventos de la Concepción y del Carmen de Osuna. Romero Torres/Moreno Soto, 2014: 55.

${ }^{67}$ Inventario de bienes de Bernarda de Benavides, 17-I-1683, Archivo de Protocolos Notariales, Granada, leg. 918, f. 71 v. Cit. en Cruz Cabrera, 2007: 122, n. 6. 


\section{Más allá del Ecce Homo: los relieves de tema hagiográfico}

La visión que de los García dio Orozco como "escultores del Ecce Homo" condicionó durante décadas la valoración de su producción, que quedó circunscrita a los temas de la pasión de Cristo. No obstante, las fuentes granadinas ampliaban el espectro de su catálogo a otros temas, como el "San Juan Baptista en el Desierto, señalando à el Cordero" que describió Parra y Cote en el camarín de San Juan de Dios (1759) ${ }^{68}$, el "San Geronimo en una gruta, hechura de los Garcias" inventariado en la catedral (1774) ${ }^{69}$, o el "Niño [...] sentado en una peña, de dichos Garcias" que vio Maule en el convento de Mercedarios Descalzos $(1812)^{70}$.

A pesar de estas antiguas noticias -y a excepción de la controvertida atribución del San Juanito de la catedral granadina-, no ha sido hasta la última década cuando Romero Torres ha conseguido rescatar para su catálogo un importante grupo de terracotas de tema hagiográfico ${ }^{71}$. Se trata por lo general de santos eremitas como san Jerónimo o el Bautista, representados en grutas o entornos agrestes en actitud de lectura, oración o éxtasis místico. Las figuras aparecen siempre recortadas sobre fondos planos sobre los que se desarrollan pequeñas pinturas de paisaje concebidas con notable destreza. Resulta éste un punto de enorme interés, que sitúa a los García al corriente de las inquietudes de los artistas del primer naturalismo, profundamente interesados en la atenta observación del natural.

Aunque ninguna de estas terracotas esté firmada, por fortuna algunas sí están datadas a través de inscripciones grabadas sobre el barro fresco. Las piezas más antiguas se fechan en el reverso, donde se consignó el día, el mes y el año de su ejecución (como hacía Pacheco con sus dibujos), mientras que las más tardías suelen mostrar el año estampillado en el borde inferior. El rango cronológico conocido abarca desde 1619 hasta 1637, por lo que coincide perfectamente con el período de actividad de los hermanos García.

Una serie de características técnicas y de formato también apuntalan la atribución a los hermanos barristas. Por ejemplo en algunas terracotas, como el San Juan Bautista fechado en 1628, se ha detectado el empleo de cera, material que conocían bien los gemelos ${ }^{72}$; y por otra parte, el tamaño de las urnas en que se insertan, de unos $40 \mathrm{~cm}$, viene a coincidir con la media vara que medía la urna descrita por Maule en el convento de Belén. Pero quizás uno de los argumentos más convincentes sea la constatación del uso de moldes, como demuestran una serie de barros de san Jerónimo prácticamente idénticos, inspirados en una estampa de Willen Van Swanenburg sobre composición de Abraham Bloemaert ${ }^{73}$, o la existencia de otra copia, hasta ahora desconocida, del Extasis de san Juan Bautista niño, que en 1918 se encontraba en colección particular y que es en todo análoga a otra existente en clausura madrileña (fig. 10) ${ }^{74}$.

La confrontación estilística con las obras seguras de los García tampoco deja lugar a dudas, pues el paralelo entre obras como el San Jerónimo datado en 1628 y las versiones del Cristo de las Penas resulta sencillamente sorprendente. Más allá de la coincidencia de tipos y expresiones, el plegado anguloso de los ropajes de estos santos encaja plenamente con el tratamiento de las telas visto en su serie pasionista. También resulta muy recurrente el detalle de las manos unidas, pero no entrelazadas, que reaparece en otras versiones de san Jerónimo, como la terracota inédi-

\footnotetext{
68 Parra y Cote, 1759: 258.

69 "Una urna de madera dorada y blanca, y en lo alto de ella una ymagen de Dolores, y con los fondos negros, digo dorados, y dentro de ella encierra un señor San Geronimo en una gruta, hechura de los Garcias; y dicha vrna tiene sus christales, y esta en dicha sacristia". Archivo de la Catedral de Granada, L. 89 de varios, f. 118v.

${ }^{70}$ Cruz y Bahamonde, 1812: 236.

71 Romero Torres, 2009.

72 Romero Torres, 2009: 72.

73 Monasterio de S. Jerónimo (Granada), Museo de Arte de Ponce (Puerto Rico), antigua col. López Vázquez y col. Granados. Romero Torres, 2009: 83.

74 En paradero desconocido, existen dos reproducciones en la fototeca del Laboratorio de Arte de la U. de Sevilla, con n. ${ }^{\circ}$ 2-1096 y 2-1097. Para el ejemplar madrileño véase Romero Torres, 2009: 66-67.
} 

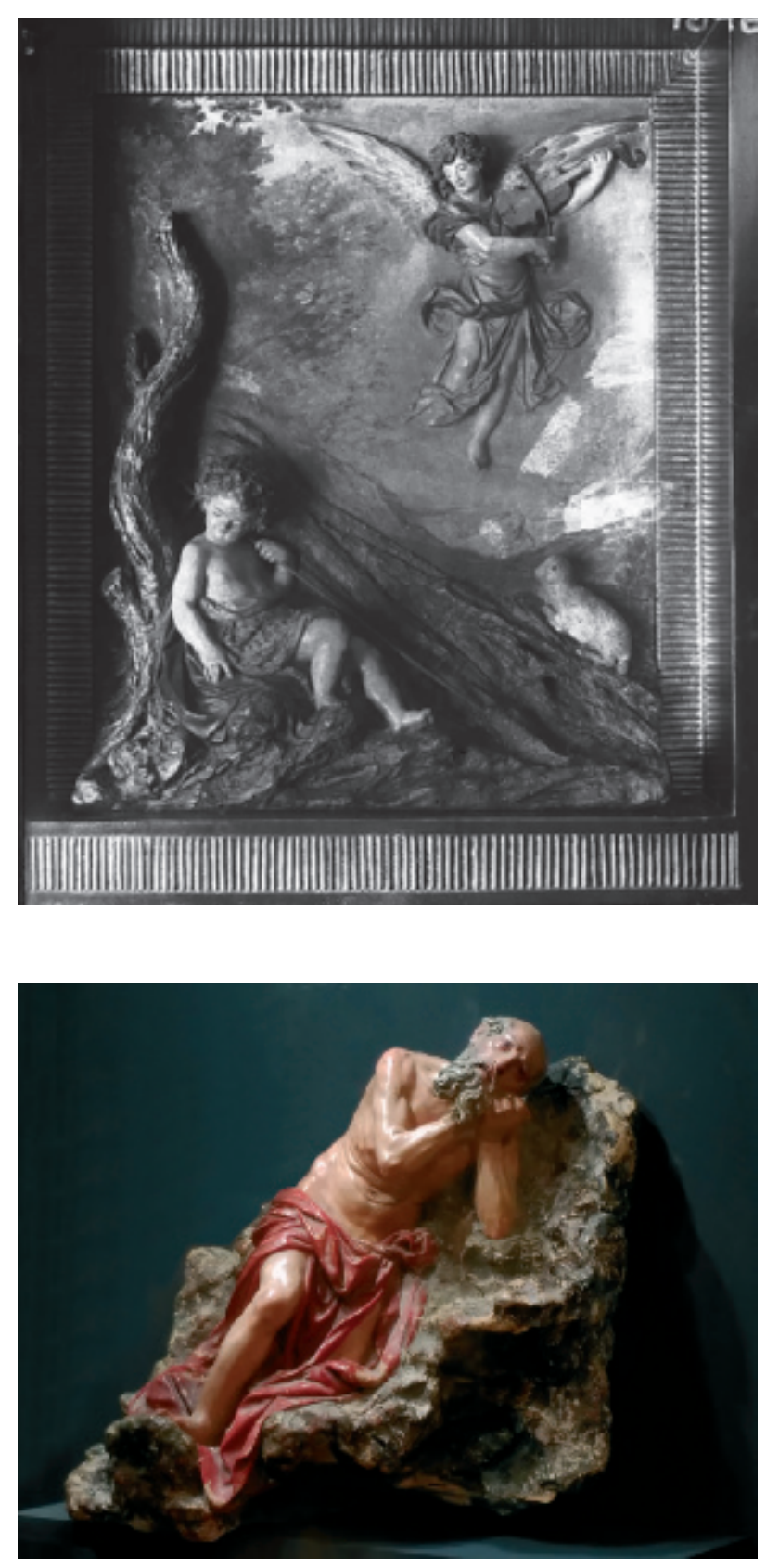

Fig. 10. Hermanos García. San Juanito confortado por el ángel o Éxtasis de San Juanito. Paradero desconocido. Fotografía: Fototeca del Laboratorio de Arte, Universidad de Sevilla.
Fig. 11. Hermanos García. San Jerónimo penitente, ca. 1610-1639. Sevilla, comercio de arte.

ta aparecida en comercio de arte sevillano (fig. 11) ${ }^{75}$ o la conservada en las Descalzas Reales de Madrid.

Tanto esta última como otros barros del tema fueron considerados obra de Alonso Cano por Sánchez-Mesa ${ }^{76}$, quien basó su atribución en la certeza de que Cano dejó unos cofres con moldes en la cartuja de Valencia y en la existencia de algún ejemplar supuestamente firmado, como el

75 Parcialmente destruida, ha perdido el león y el fondo.

76 Sánchez-Mesa Martín, 1971: 140-141. Sánchez Rivera, 2015: 251 se muestra dubitativo entre Cano y los García. 
San Jerónimo que perteneció a la colección Thyssen-Bornemisza (1633), cuya firma en realidad es completamente apócrifa $^{77}$. En estrecha dependencia con éste se encuentra otro San Jerónimo ahora en el seminario mayor de Granada, obra que podría identificarse con la documentada en la catedral en $1774^{78}$. Ambos pertenecen a la producción final de los García, como también debe serlo el conservado en el Museo Nacional de Escultura y que sin duda alguna constituye la versión más refinada del asunto (fig. 12) ${ }^{79}$. Su tardía datación (1637) justifica la evolución del modelo y el definitivo abandono de los resabios tardomanieristas que se advierten en otros barros tempranos como el del Museo de Ponce (1619).

Esta fijación por san Jerónimo -por más que fuera el santo patrón de los hermanos- hay que ponerla en relación con la popularidad que adquirieron los santos eremitas y penitentes durante la Contrarreforma, como reafirmación católica del sacramento de la penitencia. En este grupo, por supuesto, también hubo lugar para los

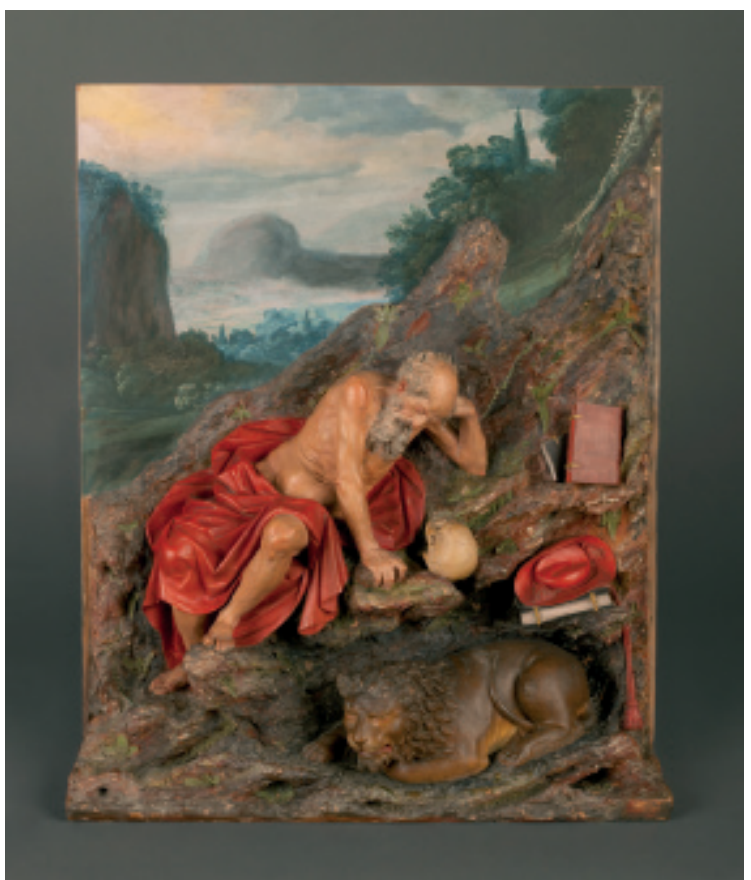

Fig. 12. Hermanos García. San Jerónimo penitente, 1637. Valladolid, Museo Nacional de Escultura. Fotografía: (C) Museo Nacional de Escultura. santos arrepentidos, como San Pedro (comercio de arte $)^{80}$ o la Magdalena, de la que se conserva al menos una terracota inédita en colección particular granadina ${ }^{81}$.

En definitiva, estas nuevas piezas vienen a añadirse al complejo rompecabezas que supone el estudio de los hermanos García y al que, con toda probabilidad, continuarán sumándose otras obras inéditas de clausuras y colecciones privadas. El hallazgo de la documentación aquí presentada, lejos de zanjar la cuestión, deja abiertos numerosos interrogantes como la formación artística de los hermanos o su relación con el mundo sevillano, cuestiones a las que sólo investigaciones futuras habrán de dar respuesta.

\section{BIBLIOGRAFÍA}

AA.VV. (1991): Historia del Colegio de San Pablo, Granada, 1554-1765: Archivo Histórico Nacional, Madrid: Ms. Jesuitas, Libro 773 [ed. de Joaquín de Béthencourt y Estanislao Olivares]. Granada: Facultad de Teología.

Alonso Moral, Roberto (2010): "La producción de escultura en barro del Manierismo al primer Naturalismo: Gaspar Núñez Delgado y los Hermanos García”. En: Gila Medina, Lázaro (coord.): La escultura del primer Naturalismo en Andalucía e Hispanoamérica (1580-1625). Madrid: Arco/Libros, pp. 333-356.

Baker, Malcolm (1992): "St Jerome in penitence". En: Radcliffe, Anthony/Baker, Malcolm/Maek-Gérard, Michael: The Thyssen-Bornemisza Collection: Renaissance and later sculpture with works of art in bronze. Milán: Electa, pp. 432434.

Bermúdez de Pedraza, Francisco (1608): Antigüedad y excelencias de Granada. Madrid: Luis Sánchez.

\footnotetext{
77 La inscripción “Al $\mathrm{C}^{\mathrm{o}} \mathrm{Fa}$." aparece en un trozo de barro añadido. Baker, 1992: 432.

78 García Luque, 2015: 788. Véase nota 69.

79 Marcos Villán, 2009 (atrib. a Cano). Romero Torres, 2009: 58 (atrib. a los García).

80 Romero Torres, 2015: 52-61.

${ }^{81}$ La santa, de perfil y semiarrodillada, se encuentra exenta por haber perdido el fondo.
} 
Bernier Luque et al. (1993): Catálogo artístico y monumental de la provincia de Córdoba, t. VI. Córdoba: Diputación Provincial.

Carrero Rodríguez, Juan (1991): "Una imagen de Jesús orante en el Gólgota de los hermanos García en Sevilla". En: Laboratorio de Arte, 4, Sevilla, pp. 317-324.

Ceán Bermúdez, Juan Agustín (1800): Diccionario histórico de los más ilustres profesores de las Bellas Artes en España, t. II. Madrid: Vda. de Ibarra.

Collado del Hierro, Agustín (2005): Granada por D. Agustín Collado del Hierro: poema del s. XVII [ed. de Carmen López Carmona]. Jaén: Universidad.

Cruz Cabrera, José Policarpo (2007): "La escultura barroca granadina. El oficio artístico al servicio de la espiritualidad". En: Henares Cuéllar, Ignacio/López Guzmán, Rafael (coms.): Antigüedad y excelencias. Sevilla: Junta de Andalucía, pp. 118-132.

Cruz y Bahamonde, Nicolás de la (1812): Viage de España, Francia è Italia, t. XII. Cádiz: Imp. de D. Manuel Bosch.

García Luque, Manuel (2013): "Fuentes grabadas y modelos europeos en la escultura andaluza (1600-1650)". En: Gila Medina, Lázaro (coord.): La consolidación del Barroco en la escultura andaluza e hispanoamericana. Granada: Universidad, pp. 179-256.

García Luque, Manuel (2015): “La lista de pinturas y esculturas ‘de mérito’ de la catedral de Granada (1792)”. En: Taín Guzmán, Miguel/Rodríguez Ortega, Nuria (eds.): Teoría y Literatura Artística en España (siglos XVI-XVIII): revisión historiográfica y estudios contemporáneos. Madrid: Real Academia de San Fernando, pp. 775-796.

Gómez-Moreno Calera, José Manuel (2005): "Pervivencia y modificaciones al ideal siloesco: de Juan de Maeda a Miguel Guerrero (1564-1650)". En: Gila Medina, Lázaro (coord.): El libro de la Catedral de Granada, t. I. Granada: Cabildo de la Catedral, pp. 129-167.

López-Guadalupe Muñoz, Juan Jesús (2009): "Sacra Natura. A propósito del Crucificado de los Hermanos García de la Sacristía Mayor de la Catedral de Granada". En: Cuadernos de Arte de la Universidad de Granada, 40, pp. 83-97.

López-Guadalupe Muñoz, Juan Jesús (2010): "Forma y expresión en los inicios del naturalismo en la escultura granadina. Lecturas y relecturas sobre los Hermanos García”. En: Gila Medina, Lázaro (coord.): La escultura del primer Naturalismo en Andalucía e Hispanoamérica (1580-1625). Madrid: Arco/Libros, pp. 207-238.

Marcos Villán, Miguel Ángel (2009): "San Jerónimo penitente". En: Museo Nacional Colegio de San Gregorio: colección. Madrid: Ministerio de Cutura, pp. 218-219.

Orozco Díaz, Emilio (1934): "Los hermanos García. Escultores del Ecce Homo”. En: Boletín de la Universidad de Granada, 30, pp. 269-286.

Orozco Díaz, Emilio (1935): "Nota adicional al trabajo sobre los hermanos García". En: Boletín de la Universidad de Granada, 33, pp. 193-194.

Palomino de Castro y Velasco, Antonio (1724): El Museo pictórico y escala óptica, t. III. Madrid: Lucas Antonio de Bédmar.

Parra y Cote, fray Alonso (1759): Desempeño... del magnifico templo... de N. P. San Juan de Dios... de Granada. Madrid: Imp. de Francisco Javier García.

Romero Torres, José Luis (2009): "Los hermanos García: Sculptors, Painters and Brothers in Sixteenth-Century Granada. An examination of their work and the shift towards naturalism in Andalusian Baroque Sculpture". En: The Mystery of Faith. An eye on Spanish Sculpture 1550-1750. Londres: The Matthiesen Gallery-Coll\&Cortés, pp. 53-83.

Romero Torres, José Luis/Moreno de Soto, Pedro Jaime (2014): A imagen y semejanza: escultura de pequeño formato en el patrimonio artístico de Osuna. Osuna: Patronato de Arte.

Romero Torres, José Luis (2015): Granada, The Mystic baroque. Madrid: Coll\&Cortés.

Salas, Xavier de (1966): Noticias de Granada reunidas por Ceán Bermúdez. Granada: Universidad.

Sánchez Rivera, Jesús Ángel (2015): "Esculturas y escultores granadinos en el Madrid del seiscientos: presencia e influencia”. En: Lecciones barrocas: “aunando miradas”. Córdoba: Asociación Hurtado Izquierdo, pp. 243-286.

Sánchez-Mesa Martín, Domingo (1971): Técnica de la escultura policromada granadina. Granada: Universidad.

Sánchez-Mesa Martín, Domingo (1991): El arte del Barroco. Escultura, Pintura y Artes decorativas. Sevilla: Gever.

Villar Movellán (1983): "Juan de Mesa y Alonso de Mena: enigmas e influencias": En: Apotheca, 3, Córdoba, pp. 101139.

Fecha de recepción: 30-V-2016

Fecha de aceptación: 8-VII-2016 